\title{
PENGARUH KARAKTERISTIK INDIVIDU DAN KARAKTARISTIK PEKERJAAN TERHADAP PERILAKU TIDAK AMAN (UNSAFE ACTION) PADA PEKERJA DIVISI KAPAL NIAGA PT. PAL INDONESIA TAHUN 2018
}

\author{
Friska Ayu, Muslikha Nourma Rhomadhoni \\ Program Studi D-IV Keselamatan dan Kesehatan Kerja \\ Fakultas Kesehatan, Universitas Nahdlatul Ulama Surabaya \\ Email: friskayuligoy@unusa.ac.id
}

\begin{abstract}
The accident that occurred was caused by two factors like unsafe act and unsafe condition. PT PAL is one of the companies that produce ships and provides ship maintenance services which every process have pontential hazard like welding process, grinding process and steel cutting process. Initial survey showed there was several accident like pinched causing minor injuries and some nearmiss to workers in the welding section. This research was conducted in Commercial Ship Division PT. PAL with aim to analyze the influence of individual characteristics and characteristics of work with unsafe act on the Commerce Division of PT. PAL using cross sectional study with total sample of as many as 80 worker. Characteristics of respondent and unsafe action was obtained from interview with workers and observation directly to the field. The result of statistical tests using binary logistic regression showed that characteristics individual and characteristics of work which has an influence on unsafe action are age $(p=0,001)$, knowledge of OHS $(p=0,000)$ and time periode $(p=0,008)$ with $R$ value $=0,690$. This means that age, knowledge of OHS and time periode have an effect of $69 \%$ on unsafe action on workers in the division of the commercial ship PT. PAL (Indonesia) and $31 \%$ are influenced by other factors. Recommendation for workers should avoid unsafe act while working like joking and for the companies should be more routine to hold socialization related implementation of $\mathrm{OSH}$ in the workplace and also increase supervision for workers, especially in the habit of using PPE in accordance with established policies.
\end{abstract}

Keywords: Unsafe Action, Commercial Ship, Shipping

\begin{abstract}
ABSTRAK
Kecelakaan yang terjadi disebabkan oleh dua faktor yaitu perilaku tidak aman dan kondisi tidak aman. PT. PAL merupakan salah satu perusahaan yang memproduksi kapal dan menyediakan jasa pemeliharaan kapal serta rekayasa umum, dimana dalam setiap proses pengerjaannya memiliki risiko bahaya yang tinggi seperti pekerjaan pengelasa, penghalusan dan pemotongan baja. Hasil survey awal menunjukkan telah terjadi beberapa accident seperti terjepit yang menimbulkan cidera ringan serta beberapa kejadian nearmiss (nyaris celaka) pada pekerja di bagian pengelasan. Penelitian ini dilakukan di Divisi Kapal Niaga PT.PAL dengan tujuan untuk menganalisis pengaruh karakteristik individu dan karakteristik pekerjaan dengan perilaku tidak aman pada pekerja Divisi Niaga PT.PAL Indonesia dengan menggunakan rancangan cross sectional dengan besar sampel
\end{abstract}


sebanyak 80 orang. Data terkait karakteristik responden, pekerjaan dan perilaku tidak aman diperoleh dari hasil wawancara dengan para pekerja dan pengamatan langsung ke lapangan. Hasil uji statistik menggunakan regresi binary logistik menunjukkan bahwa karakteristik individu dan karakteristik pekerjaan yang memilki pengaruh terhadap perilaku tidak aman adalah umur $(\mathrm{p}=0,001)$, pengetahuan akan $\mathrm{K} 3(\mathrm{p}=0,000)$ dan masa kerja $(\mathrm{p}=0,008)$ dengan nilai $\mathrm{R}=0,690$. Hal ini berarti umur, pengetahuan akan K3 dan masa kerja memiliki pengaruh sebesar $69 \%$ terhadap perilaku tidak aman (unsafe action) pada pekerja di bagian divisi kapal niaga PT. PAL (Indonesia) dan $31 \%$ dipengaruhi oleh faktor lainnya. Disarankan bagi pekerja sebaiknya menghindari perilaku yang tidak aman saat bekerja seperti bersenda gurau saat bekerja. Bagi pihak perusahaan sebaiknya lebih rutin mengadakan sosialisasi terkait tujuan penerapan K3 ditempat kerja dan juga meningkatkan pengawasan bagi pekerja terutama dalam kebiasaan penggunaan APD sesuai dengan kebijakan yang telah ditetapkan.

Keywords: Unsafe Action, Divisi Niaga, Perkapalan

\section{PENDAHULUAN}

Perlindungan tenaga kerja meliputi beberapa aspek salah satunya pelindungan keselamatan dan kesehatan pekerja. Perlindungan keselamatan merupakan salah satu upaya yang dilakukan perusahaan melindungi tenaga kerja secara aman dalam melakukan pekerjaanya sehari-hari serta dapat mencegah terjadinya kecelakaan kerja, kecelakaan yang terjadi diakibatan dari dua faktor yaitu perilaku tidak aman (unsafe action) dan kondisi tidak aman (unsafe condition).

Data dari International Labour Organization (ILO) setiap hari terjadi sekitar 6.000 kecelakaan kerja fatal di dunia, lebih dari 160 juta pekerja menjadi sakit karena bahaya/ tindakan tidak aman di tempat kerja. ${ }^{1}$ Hal ini dipengaruhi seperti alat-alat yang tidak layak pakai, alat pengaman yang kurang memenuhi standar. ${ }^{2}$ Tindakan tidak aman (unsafe action) adalah tindakan yang dapat membahayakan pekerja itu sendiri. $^{3}$
Di Indonesia angka kecelakaan kerja masih tergolong cukup tinggi, pada akhir tahun 2015 telah terjadi kecelakaan kerja sebanyak 105.182 kasus, untuk kasus kecelakaan berat yang mengakibatkan kematian tercatat sebanyak 2.375 kasus dari total jumlah kecelakaan kerja. $^{4}$

PT.PAL Indonesia (Persero) merupakan perusahaan galangan kapal, kegiatan utama perusahaan ini adalah memproduksi kapal perang, kapal niaga, kapal selam, dan menyediakan jasa perbaikan dan pemeliharaan kapal, jenis pekerjaan paling sering dilakukan oleh para pekerja Divisi Kapal Niaga adalah pengelasan, gerinda, fitter, painting. Hasil survey awal yang dilakukan dari bulan februarimei 2018, telah terjadi beberapa accident seperti terjepit yang menimbulkan cidera ringan serta beberapa kejadian nearmiss (nyaris celaka) pada pekerja di bagian pengelasan (welding) dan pekerja pemotongan baja (fitting). 
Oleh karena itu, perlu diadakan penilaian tentang pengaruh karakteristik responden dengan karakteristik pekerjaan terhadap perilaku tidak aman (unsafe action) pada pekerja divisi kapal niaga PT. PAL Indonesia.

\section{METODE PENELITIAN}

Desain penelitian ini termasuk dalam survey analitik dengan rancangan cross sectional study. Populasi dalam penelitian ini adalah seluruh pekerja tetap Divisi Kapal Niaga PT. PAL Indonesia. Data yang diperoleh dari Departemen Support dapat diketahui bahwa pegawai lapangan PKWT berjumlah 100 orang. Pengambilan jumlah besar sampel dilakukan dengan menggunakan rumus slovin. Cara pengambilan sampel pekerja pada penelitian ini adalah dengan cara cluster, kemudian di distrubusi kedalam 3 departemen yakni departemen Erection sebanyak 36 orang, Departemen MO/EO sebanyak 20 orang dan Departemen HO/AO sebanyak 24 orang.

Data primer terkait karakteristik individu dan karakteristik pekerjaan diperoleh dari hasil wawancara dengan pekerja yang menjadi responden dalam kegiatan penelitian ini dan hasil observasi yang dilakukan di divisi kapal niaga. Terkait data sekunder seperti profil perusahaan, deskripsi pekerjaan dan program keselamatan dan kesehatan kerja (K3) diperoleh dari perusahaan PT.PAL Indonesia. Data yang telah dikumpulkan kemudian diolah menggunakan program SPSS dan dianalisis data dilakukan dengan uji statistik menggunakan uji Logistic regression (Regresi Logistik Biner)

\section{HASIL DAN PEMBAHASAN}

\section{Karakteristik Responden}

Tabel 1. Distribusi Karakteristik individu Pada Pekerja di Divisi Kapal Niaga PT.PAL (Indonesia)

\begin{tabular}{|c|c|c|c|}
\hline $\begin{array}{l}\text { Karakteristik } \\
\text { individu }\end{array}$ & Kategori & $\mathrm{n}$ & $\%$ \\
\hline \multirow{2}{*}{ Umur } & $>40$ Tahun & 21 & 26.2 \\
\hline & $\leq 40$ Tahun & 59 & 73.8 \\
\hline \multirow{2}{*}{$\begin{array}{l}\text { Pendidikan } \\
\text { Terakhir }\end{array}$} & SMA/SMK & 23 & 28.8 \\
\hline & $\begin{array}{l}\text { Perguruan } \\
\text { Tinggi }\end{array}$ & 57 & 71.3 \\
\hline \multirow{4}{*}{ Jenis Pekerjaan } & $\begin{array}{l}\text { Pengelasan } \\
\text { (Welding) }\end{array}$ & 32 & 40.0 \\
\hline & $\begin{array}{l}\text { Gerinda } \\
\text { (Gerinding) }\end{array}$ & 13 & 16.2 \\
\hline & $\begin{array}{l}\text { Pemotongan } \\
\text { Baja } \\
\text { (Fitting) }\end{array}$ & 19 & 23.8 \\
\hline & $\begin{array}{l}\text { Pengecatan } \\
\text { (Painting) }\end{array}$ & 16 & 20.0 \\
\hline \multirow{2}{*}{ Masa Kerja } & $>5$ Tahun & 56 & 70.0 \\
\hline & $\leq 5$ Tahun & 24 & 30.0 \\
\hline \multirow{2}{*}{$\begin{array}{l}\text { Perilaku Tidak } \\
\text { Aman } \\
\text { (Unsafe Action) }\end{array}$} & Sering & 31 & 38.8 \\
\hline & Jarang & 49 & 61.3 \\
\hline \multirow{2}{*}{$\begin{array}{l}\text { Pengetahuan } \\
\text { tentang K3 }\end{array}$} & Cukup Baik & 30 & 37.5 \\
\hline & Baik & 50 & 62.5 \\
\hline \multirow{2}{*}{$\begin{array}{l}\text { Kebiasaan } \\
\text { Penggunaan } \\
\text { APD }\end{array}$} & $\begin{array}{l}\text { Cukup } \\
\text { Patuh }\end{array}$ & 28 & 35.0 \\
\hline & Patuh & 52 & 65.0 \\
\hline \multirow{2}{*}{$\begin{array}{l}\text { Mengikuti } \\
\text { Pelatihan }\end{array}$} & Jarang & 34 & 42.5 \\
\hline & Saring & 46 & 57.5 \\
\hline \multicolumn{2}{|c|}{ Jumlah } & 80 & 100.0 \\
\hline
\end{tabular}

Sumber: Data Primer, 2018

Data Tabel 1 tentang distribusi karakteristik responden pada pekerja di Divisi Kapal Niaga PT. PAL (Indonesia) 
menunjukkan bahwa sebagian besar pekerja yang menjadi responden dalam penelitian ini merupakan pekerja bagian pengelasan (Welding) yakni sebanyak 32 orang (40\%) dan pekerja yang paling sedikit adalah pekerja bagian gerinda (Gerinding) yakni sebanyak 13 orang (16,2\%). Usia pekerja sebagian besar kurang dari 40 Tahun $(73,8 \%)$ dengan pendidikan terakhir sebagian besar adalah perguruan tinggi, baik itu program diploma dan sarjana yakni sebanyak 57 orang (71.3\%), dimana 56 orang diantaranya memiliki masa kerja lebih dari 5 tahun.

Hasil wawancara dengan responden mengenai tingkat pengetahuan $\mathrm{K} 3$ dalam hal ini tentang faktor bahaya dan risiko kesehatan dari pekerjaan yang dilakukan oleh pekerja, menunjukkan bahwa tingkat pengetahuan para pekerja tentang $\mathrm{K} 3$ sudah sangat baik, karena sebanyak 50 orang $(62,5 \%)$.

\section{Pengaruh Karakteristik Individu Terhadap}

\section{Perilaku Tidak Aman}

Tabel 2. Uji Pengaruh antara Karakteristik individu terhadap Perilaku Tidak Aman Pada Pekerja di Divisi Kapal Niaga PT.PAL (Indonesia)

\begin{tabular}{lcc}
\hline \multirow{2}{*}{ Variabel Independen } & \multicolumn{2}{c}{$\begin{array}{c}\text { Variabel Dependen: } \\
\text { Perilaku Tidak Aman } \\
\text { (unsafe action) }\end{array}$} \\
\cline { 2 - 3 } & $\begin{array}{c}\text { Nilai } \\
\text { Peluang } \\
\text { (P-value) }\end{array}$ & $\begin{array}{c}\text { Nilai Besar } \\
\text { Risiko } \\
\text { (OR) }\end{array}$ \\
\hline Umur & 0.000 & 0.048 \\
Pengetahuan K3 & 0.000 & 17.250 \\
Tingkat Pendidikan & 0.001 & 6.400 \\
Mengikuti Pelatihan & 0.002 & 4.545 \\
\hline
\end{tabular}

Sumber: Data Primer, 2018
Data Tabel 2 tentang uji pengaruh antara karakteristik individu dengan perilaku tidak aman (unsafe action) pada pekerja menggunakan uji regresi linear sederhana menunjukkan bahwa umur, tingkat pendidikan, tingkat pengetahuan dan kebiasaan mengikuti pelatihan memiliki pengaruh terhadap perilaku tidak aman pada pekerja di divisi kapal niaga, hal ini dapat di liat dari nilai $\mathrm{p}$ value $<0,05$. Namun dari 4 faktor individu yang paling berpengaruh terhadap perilaku tidak aman adalah pengetahuan $\mathrm{K} 3$, dapat dilihat dari nilai besar risiko $(\mathrm{OR}=17,250)$. Hal ini berarti pengetahuan akan K3 yang cukup baik berisiko 17 kali terhadap perilaku tidak aman dibandingkan pengetauan yang baik.

\section{Pengaruh Karakteristik Pekerjaan Terhadap Perilaku Tidak Aman}

Tabel 3. Uji Pengaruh antara Karakteristik Pekerjaan terhadap Perilaku Tidak Aman Pada Pekerja di Divisi Kapal Niaga PT.PAL (Indonesia)

\begin{tabular}{lcc}
\hline & \multicolumn{2}{c}{$\begin{array}{c}\text { Variabel Dependen: } \\
\text { Perilaku Tidak Aman (unsafe } \\
\text { Vaction) }\end{array}$} \\
\cline { 2 - 3 } $\begin{array}{c}\text { Independen } \\
\text { Nilabel }\end{array}$ & $\begin{array}{c}\text { Nilai } \\
\text { Peluang } \\
\text { (P-value) }\end{array}$ & $\begin{array}{c}\text { Nilai Besar } \\
\text { Risiko } \\
\text { (OR) }\end{array}$ \\
\hline $\begin{array}{l}\text { Masa Kerja } \\
\text { Kebiasaan }\end{array}$ & 0.000 & 0.101 \\
$\begin{array}{l}\text { Penggunaan } \\
\text { APD }\end{array}$ & 0.000 & 17.519 \\
Jenis Pekerja & 0.217 & 1.281 \\
\hline
\end{tabular}

Sumber: Data Primer, 2018

Data Tabel 3 tentang uji pengaruh antara karakteristik pekerjaan dengan perilaku tidak aman (unsafe action) pada pekerja menggunakan uji regresi linear sederhana 
menunjukkan bahwa dari tiga faktor pekerjaan yang paling berpengaruh terhadap perilaku tidak aman (unsafe action) pada pekerja di divisi kapal niaga adalah kebiasaan penggunaan alat pelindung diri, kebiasaan penggunaan APD dalam penelitian ini dikategorikan menjadi 2 yakni kategori baik dimana hasil observasi penggunaan APD di lapangan sesuai dengan jawaban responden saat diwawancarai, artinya pekerja disiplin dalam penggunaan APD, sedangkan kategori cukup baik adalah dimana hasil observasi penggunaan APD di lapangan tidak sesuai dengan jawaban responden ataupun sebaliknya.

\section{Uji Multivariat antara karakteristik} individu dan pekerjaan terhadap perilaku tidak aman pada pekerja Divisi Kapal Niaga PT.PAL (Indonesia)

Tabel 4. Ringkasan Hasil Uji Regresi Tentang Pengaruh Karakteristik individu dan Karakteristik Pekerjaan terhadap Perilaku Tidak Aman Pada Pekerja di Divisi Kapal Niaga PT.PAL (Indonesia)

\begin{tabular}{|c|c|c|c|c|}
\hline $\begin{array}{l}\text { Variabel } \\
\text { Independen }\end{array}$ & $\begin{array}{c}\text { P- } \\
\text { Value }\end{array}$ & OR & $\mathrm{R}$ & Ket \\
\hline Umur & 0.001 & 0.048 & \multirow{3}{*}{0.690} & Signifikan \\
\hline $\begin{array}{l}\text { Pengetahuan } \\
\text { K3 }\end{array}$ & 0.000 & 14.985 & & Signifikan \\
\hline Masa Kerja & 0.008 & 0.127 & & Signifikan \\
\hline
\end{tabular}

Sumber: Data Primer, 2018

Data Tabel 4 menunjukkan ringkasan hasil uji regresi tentang pengaruh karakteristik individu dan karakteristik pekerjaan terhadap perilaku tidak aman (unsafe action) pada pekerja di Divisi Kapal Niaga PT.PAL
(Indonesia) menggunakan uji regresi binary logistik. Dari tujuh (7) variabel karakteristik individu dan karakteristik pekerjaan, yang memiliki pengaruh terhadap perilaku tidak aman (unsafe action) pada pekerja di divisi niaga adalah umur $(\mathrm{p}=0,001)$, pengetahuan $\mathrm{K} 3$ $(\mathrm{p}=0,000)$ dan masa kerja $(\mathrm{p}=0,008)$, dengan nilai R 0,690. Hal ini berarti umur, pengetahuan akan K3 dan masa kerja memiliki pengaruh sebesar $69 \%$ terhadap perilaku tidak aman (unsafe action) pada pekerja di bagian divisi kapal niaga PT. PAL (Indonesia) dan 31\% dipengaruhi oleh faktor lainnya.

PT. PAL memiliki beberapa divisi dengan fungsi yang berbeda-beda. Divisi Kapal Niaga merupakan salah satu divisi yang bernaung dibawah Direktorat Pembangunan Kapal yang memproduksi kapal-kapal niaga internasional, dimana proses pengerjaan dengan risiko bahaya yang tinggi, sehingga perlu pengawasan khususnya di bidang keselamatan dan kesehatan kerja, salah satu bagian yang bertanggungjawab terkait K3 di Divisi Niaga PT. PAL adalah departemen Health Safety Environment (HSE).

Perilaku manusia dipengaruhi oleh dua faktor pokok, yaitu faktor perilaku (behavior causes) dan faktor diluar perilaku (non behaviour causes). ${ }^{5}$ Perilaku itu sendiri ditentukan atau terbentuk dari 3 faktor yaitu: (1) faktor predisposisi, seperti pengetahuan, sikap, afeksi, kognisi dan perilaku, (2) faktor pemungkin, seperti fasilitas yang ada 
lingkungan pekerjaan/ tempat kerja dan (3) faktor penguat seperti aturan yang diterapkan. ${ }^{5}$

Penelitian ini bertujuan untuk menganalisis pengaruh faktor individu yang meliputi 4 variabel umur, tingkat pendidikan, pengetahuan akan K3 dan pelatihan yang di ikuti dan faktor pekerjaan yang meliputi jenis pekerjaan, masa kerja dan kebiasaan penggunaan alat pelindung diri (APD) pada pekerja di divisi niaga PT. PAL Indonesia.

Dalam kegiatan penelitian ini sebagian sebagian besar pekerja di Divisi Kapal Niaga telah menerapkan perilaku aman dalam bekerja $(61,25 \%)$, namun masih ada sebesar $(38,75 \%)$ pekerja yang masih berperilaku tidak aman (unsafe action). Data terkait perilaku tidak aman ini dikumpulkan melalui metode wawancara dan pengamatan langsung pada pekerja, saat wawancara hampir seluruh pekerja sudah berperilaku aman, namun ketika dilakukan pengamatan langsung pada pekerja, saat melakukan pekerjaannya, masih ditemukan beberapa pekerja yang berperilaku tidak aman, seperti bercanda dengan temannya, tidak memakai APD yang standar saat melakukan aktivitas kerjanya, masih di temukan beberapa pekerja yang tidak meletakkan alat kerjanya ke tempat semula.

\section{Pengaruh Karakteristik Individu terhadap} Perilaku Tidak Aman (Unsafe Action)

Karakteristik individu yang diamati dalam penelitian ini meliputi umur, tingkat pendidikan, pengetahuan K3 dan kebiasaan mengikuti pelatihan. Umur dalam penelitian ini merupakan rentang usia yang dimiliki oleh pekerja yang terhitung sejak lahir sampai kegiatan penelitian ini dilakukan.

Umur dalam penelitian ini dikategorikan menjadi dua kelompok yakni usia kurang 40 tahun dan usia diatas 40 tahun, sebagian besar pekerja yang menjadi responden dalam penelitian ini yang berusia diatas 40 tahun dengan pendidikan tingkat lulusan perguruan tinggi baik ahli madya maupun sarjana sudah melakukan perilaku aman dalam bekerja, namun para pekerja yang tidak melakukan perilaku aman dalam bekerja, sebagian besar berusia dibawa 40 tahun. Adapun pengetahuan akan K3 dalam kategori sudah sangat baik yakni sebanyak 42 orang $(73,28 \%)$ karena pekerja juga sering diikutkan pelatihan yang berhubungan dengan K3 maupun yang berhubungan dengan skill pekerjaannya.

Hasil uji statistik menggunakan regresi linear sederhana menunjukkan umur $(\mathrm{p}=0,000)$, tingkat pendidikan $(\mathrm{p}=0,000)$, pengetahuan $\mathrm{K} 3$ $(\mathrm{p}=0,001)$ dan mengikuti pelatihan $(\mathrm{p}=0,002)$, $\mathrm{P}<0,05$ berarti bahwa terdapat pengaruh karakteristik individu dalam hal ini adalah umur, tingkat pendidikan, pengetahuan akan K3 dan kebiasaan mengikuti pelatihan terhadap perilaku tidak aman (unsafe action).

Umur biasanya dikaitkan dengan kualitas kinerja seseorang, yakni semakin bertambahnya usia maka kinerjanya semakin 
menurun, hal ini dikarenakan keterampilan fisik yang dimiliki seseorang seperti yang berhubungan dengan kemampuan koordinasi, kecepatan dan kekuatan seseorang akan menurun seiring bertambahnya usia. ${ }^{6}$

Hasil penelitian ini menunjukkan bahwa perilaku tidak aman (unsafe action) justru lebih banyak dilakukan oleh pekerja yang berusia muda yakni dibawah 40 Tahun, hal ini sejalan dengan teori yang menyatakan bahwa pekerja dengan usia yang relatif muda secara psikologis akan melakukan kegiatan pekerjaanya cenderung lebih cepat, agresif dan tergesa-gesa sehingga akan melakukan tindakan yang tidak aman yang nantinya berisiko untuk mengalami kecelakaan kerja.

Hasil penelitian ini tidak sejalan dengan penelitian yang dilakukan oleh Pratama yang menyatakan bahwa unsafe action biasanya dilakukan oleh pekerja yang berusia tua (diatas 45 tahun) sebesar 18,3\% dikarenakan terjadinya penuruanan keadaan fisik, intelektual, ingatan jangka pendek dan kecepatan pengambilan keputusan sehingga pekerja yang berusia tua cenderung akan melakukan pekerjaan yang monoton yang dapat mengakibatkan sering melakukan tindakan-tindakan yang hampir berbahaya (nearmiss). ${ }^{7}$

Tingkat pengetahuan seseorang erat kaitannya dengan tingkat pendidikan seseorang, karena tingkat pendidikan berhubungan dengan daya tangkap dan daya serap informasi yang terima oleh seseorang. Pengetahuan yang dimiliki oleh seseorang merupakan faktor yang sangat berperan dalam merangsang dan mengintrepretasikan stimulus yang diperoleh.

Hasil penelitian ini menunjukkan bahwa beberapa orang pekerja yang memiliki tingkat pendidikan SMA/SMK dan memiliki pengetahuan akan K3 dalam kategori cukup masih melakukan perilaku tidak aman (Unsafe Action) saat bekerja, hal ini dikarenakan tingkat pendidikan merupakan faktor predisposisi seseorang dalam berperilaku dan pendidikan. Jadi tingkat pendidikan akan menentukan luasnya pengetahuan dan bagaimana seseorang itu bersikap. Hal ini sejalan dengan teori yang disampaikan oleh Notoadmodjo bahwa seseorang yang berpendidikan rendah akan susah untuk menyerap informasi dan inovasi baru sehingga akan mempersulit dalam dirinya dalam melakukan suatu perubahan. ${ }^{5}$

Kebiasaan mengikuti pelatihan yang dimaksud dalam penelitian ini adalah Pelatihan yang diikuti oleh responden selama menjadi pegawai di PT. PAL, mulai dari pelatihan ahli K3 Umum, pelatihan yang berhubungan dengan kemampuan/ skill masing-masing jenis pekerjaan seperti pengelasan, pemotongan baja, grinding maupun pengecatan.

\section{Pengaruh Karakteristik Pekerjaan terhadap}

\section{Perilaku Tidak Aman (Unsafe Action)}

Pada kategori pekerjaan yang diamati dalam penelitian ini yakni masa kerja, kebiasaan penggunaan alat pelindung diri dan jenis pekerjaan. Sebagian besar masa kerja 
diatas 5 tahun dengan kebiasaan penggunaan alat pelindung diri dalam kategori Baik dengan jenis pekerjaan yang paling banyak dilakukan adalah pengelasan (Welding). Perilaku tidak aman (unsafe action). Hasil uji statistik menggunakan regresi linear sederhana menunjukkan masa kerja $(\mathrm{p}=0,000)$ dan kebiasaan penggunaan alat pelindung diri (APD) $(p=0,000)$ memiliki pengaruh terhadap perilaku tidak aman (unsafe action).

Masa kerja yang dimaksud dalam penelitian ini adalah waktu kerja responden saat mulai bekerja di perusahaan sampai dilakukan penelitian ini. Masa kerja dikategorikan menjadi dua yakni masa kerja diatas 5 tahun dan kurang dari 5 tahun, sedangkan kebiasaan penggunaan APD adalah kebiasaan yang dilakukan oleh pekerja untuk memakai APD sebelum bekerja yang dilakukan atas dasar kemauan sendiri dengan atau tanpa pengawasan dari pihak HSE yang dikategorikan menjadi dua yakni baik dan cukup baik, kategori baik apabila hasil wawancara dengan responden terkait kebiasaan penggunaan APD sesuai dengan kenyataan di lapangan saat dilakukan pengamatan langsung.

Hasil penelitian ini menunjukkan bahwa pekerja dengan masa kerja diatas 5 tahun dan dengan kebiasaan penggunaan APD dalam kategori baik sudah tidak melakukan perilaku yang tidak aman dalam bekerja, dibandingkan dengan pekerja dengan masa kerja dibawah 5 Tahun dengan kebiasaan penggunaan alat pelindung diri dalam kategori cukup masih melakukan perilaku yang tidak aman (unsafe action). Seseorang akan waspada terhadap kecelakaan kerja akan bertambah seiring dengan bertambahnya masa kerja dan lama kerja di tempat kerja. ${ }^{8}$

Hal ini sejalan dengan teori dari Max Weber yang menyatakan bahwa seseorang akan melakukan suatu tindakan sesuai dengan pengalaman yang dimiliki olehnya. Hasil penelitian ini juga didukung oleh penelitian yang dilakukan oleh Iraj yang menyebutkan bahwa semakin bertambahnya masa kerja maka akan semakin rendah presentase pekerja untuk melakukan perilaku yang tidak aman (unsafe action). ${ }^{9}$

Kebiasaan penggunaan alat pelindung diri (APD) berpengaruh terhadap perilaku tidak aman (unsafe action). Dalam penelitian ini pekerja yang memiliki kebiasaan penggunaan APD dalam kategori cukup ini dikarenakan kurangnya keterampilan dan pengetahuan pekerja terkait manfaat dari penggunaan APD. Hasil penelitian ini sesuai dengan penelitian Thanet Aksorn dan Hadikusumo pada pekerja konstruksi di Thailand yang menyatakan bahwa perilaku tidak aman (unsafe action) yang sering dilakukan yakni kegagalan dalam penggunaan APD. ${ }^{9}$ 


\section{SIMPULAN DAN SARAN}

\section{Simpulan}

Dari hasil penelitian yang dilakukan dapat disimpulkan bahwa:

1. Pada pekerja divisi niaga yang menjadi responden dalam penelitian ini sebanyak 80 orang pekerja. Sebanyak 31 orang $(38,75 \%)$ pekerja masih berperilaku tidak aman dan sisanya sebanyak 49 orang $(61,25 \%)$ sudah jarang bahkan tidak pernah melakukan perilaku tidak aman saat bekerja.

2. Karakteristik individu yang berpengaruh terhadap perilaku tidak aman (unsafe action) meliputi umur ( $\mathrm{p}=0.000)$, tingkat pendidikan $(\mathrm{p}=0.000)$, pengetahuan akan K3 ( $\mathrm{p}=0.001)$ dan kebiasaan mengikuti pelatihan $(\mathrm{p}=0.002)$. Namun dari 4 faktor individu yang paling berpengaruh terhadap perilaku tidak aman adalah pengetahuan $\mathrm{K} 3$, dapat dilihat dari nilai besar risiko $(\mathrm{OR}=17,250)$. Hal ini berarti pengetahuan akan K3 yang cukup baik berisiko 17 kali terhadap perilaku tidak aman dibandingkan pengetauan yang baik.

3. Karakteristik pekerjaan yang berpengaruh terhadap perilaku tidak aman (unsafe action) adalah masa kerja $(\mathrm{p}=0.000)$ dan kebiasaan penggunaan APD $(\mathrm{p}=0.000)$. Kebiasaan penggunaan APD memiliki pengaruh sebanyak 17 kali terhadap perilaku tidak aman dibandingkan dengan kebiasaan penggunaan APD yang baik.

4. Hasil uji binary logistik antara karakteristik individu dan pekerjaan menunjukkan umur, pengetahuan akan K3 dan masa kerja memiliki pengaruh sebesar $69 \%$ terhadap perilaku tidak aman (unsafe action).

\section{Saran}

Maka disarankan kepada pihak perusahaan perusahaan sebaiknya meningkatkan pengawasan bagi pekerja terutama dalam kebiasaan penggunaan alat pelindung diri dan perilaku tidak aman yang dilakukan saat bekerja dan bagi pekerja sebaiknya menghindari perilaku yang tidak aman saat bekerja seperti bersenda gurau saat bekerja, berperilaku 5R (Ringkas, Rapi, Resik, Rawat dan Rajin).

\section{REFERENSI}

1. ILO. Health and Safety in Work Place for Productivity. Geneva: International Labour Office. 2013.

2. Anizar. Teknik Keselamatan dan Kesehatan Kerja di Industri. Yogyakarta: Graham Ilmu. 2009.

3. Suma'mur. Higiene Perusahaan dan Kesehatan Kerja (HIPERKES) Edisi 2. Jakarta: CV Sagung Seto. 2013.

4. Kemenkes RI. Menteri Ketenagakerjaan canangkan peringatan bulan K3 Nasional. http://www.depkes.go.id/article/view/180 12200004/menaker-hanif-canangkanperingatan-bulan-k3-nasional-2018.html sitasi, juli 2018. 2018.

5. Notoadmodjo. Kesehatan Masyarakat, Ilmu dan Seni. Jakarta: Penerbit Rineka Cipta. Jakarta. 2013. 
6. Suma'mur. Hiegiene Perusahaan dan Keselamatan Kerja. Jakarta: CV Sagung Seto. 2009.

7. Pratama, A.K. Hubungan antara karakteristik pekerja dan tipe kepribadian dengan unsafe action pada Tenaga Kerja Bongkar Muat di PT. Terminal Petikemas Surabaya. Skripsi, Surabaya, Universitas Airlangga. 2015.

8. Saragih, F.R. Faktor yang berhubungan dengan tindakan tidak aman pada pekerja lapangan PT. Telkom Cabang Sidikalang Kabupaten Dairi. Universitas Sumatera Utara. 2014.

9. Iraj, M.F. jurnal Evaluation of Relationship Between Job Stress and Unsafe Acts With Occupational Accident Rates in a Vehicle Manufacturing in Iran. Iran: http://Internasional .com. Diakses tanggal 9 Juli 2018. 2012. 